\title{
BMJ Open Spatial distribution and determinant factors of anaemia among women of reproductive age in Ethiopia: a multilevel and spatial analysis
}

Kelemu Tilahun Kibret, ${ }^{1}$ Catherine Chojenta, ${ }^{1}$ Ellie D'Arcy, ${ }^{1,2}$ Deborah Loxton ${ }^{1}$

To cite: Kibret KT, Chojenta C, D'Arcy E, et al. Spatial distribution and determinant factors of anaemia among women of reproductive age in Ethiopia: a multilevel and spatial analysis. BMJ Open 2019;9:e027276. doi:10.1136/ bmjopen-2018-027276

- Prepublication history and additional material for this paper are available online. To view these files, please visit the journal online (http://dx.doi org/10.1136/bmjopen-2018027276).

Received 16 0ctober 2018 Revised 23 January 2019 Accepted 18 February 2019
Check for updates

(C) Author(s) (or their employer(s)) 2019. Re-use permitted under CC BY-NC. No commercial re-use. See rights and permissions. Published by BMJ.

${ }^{1}$ Priority Research Center for Generational Health and Aging, School of Medicine and Public Health, University of Newcastle, Newcastle, New South Wales, Australia

${ }^{2}$ Western New South Wales, Local Health District, Dubbo, New South Wales, Australia

Correspondence to Mr Kelemu Tilahun Kibret; ktwu27@gmail.com

\section{ABSTRACT}

Objective The aim of this study was to assess the spatial distribution and determinant factors of anaemia among reproductive age women in Ethiopia.

Methods An in-depth analysis of the 2016 Ethiopian Demographic and Health Survey data was undertaken. Getis-Ord Gi* statistics were used to identify the hot and cold spot areas for anaemia among women of reproductive age. A multilevel logistic regression model was used to identify independent predictors of anaemia among women of reproductive age.

Results Older age (adjusted OR $[A 0 R]=0.75 ; 95 \% \mathrm{Cl}$ 0.64 to 0.96 ), no education ( $\mathrm{AOR}=1.37 ; 95 \% \mathrm{Cl} 1.102$ to 1.72), lowest wealth quantile $(A O R=1.29 ; 95 \% \mathrm{Cl} 1.014$ to 1.60$)$, currently pregnant $(\mathrm{AOR}=1.28 ; 95 \% \mathrm{Cl} 1.10$ to 1.51 , currently breast feeding ( $\mathrm{AOR}=1.09 ; 95 \% \mathrm{Cl}$ 1.025 to 1.28 ), high gravidity ( $\mathrm{AOR}=1.39 ; 95 \% \mathrm{Cl} 1.13$ to 1.69) and HIV positive (AOR=2.11; $95 \% \mathrm{Cl} 1.59$ to 2.79) are individual factors associated with the occurrence of anaemia. Likewise, living in a rural area $(A O R=1.29$; $95 \% \mathrm{Cl} 1.02$ to 1.63 ) and availability of unimproved latrine facilities (AOR=1.18; 95\% $\mathrm{Cl} 1.01$ to 1.39) are communitylevel factors associated with higher odds of anaemia. The spatial analysis indicated that statistically high hotspots of anaemia were observed in the eastern (Somali, Dire Dawa and Harari regions) and north-eastern (Afar) parts of the country.

Conclusion The prevalence rate of anaemia among women of reproductive age varied across the country. Significant hotspots/high prevalence of anaemia was observed in the eastern and north-eastern parts of Ethiopia. Anaemia prevention strategies need to be targeted on rural residents, women with limited to no education, women who are breast feeding, areas with poor latrine facilities and women who are HIV positive.

\section{INTRODUCTION}

Anaemia refers to a low haemoglobin level $(<110 \mathrm{~g} / \mathrm{L}$ for pregnant women and $<120 \mathrm{~g} / \mathrm{L}$ for non-pregnant women). ${ }^{1}$ If an individual's haemoglobin level is low, the red blood cells are unable to carry adequate oxygen for the body's physiological needs. ${ }^{1}$ Anaemia is a major public health problem in women and children under 5 years of age. ${ }^{2}$

\section{Strengths and limitations of this study}

- Used large population-based data with a large sample size, which is representative of all regions of the country.

- A combination of statistical methods (spatial analysis and multilevel logistics analysis) were applied, which allows understanding of the role of contextual and geographical factors in the occurrence of anaemia among women of reproductive age.

- The cause/effect and temporal relationship could not be established due to the cross sectional nature of the data.

- Essential factors such as dietary intake and behavioural factors were unable to be incorporated in the analysis.

Worldwide, $38 \%$ of pregnant women and $29 \%$ of non-pregnant women were anaemic in 2011. ${ }^{2}$ Pregnant women in low-income and middle-income countries (LMICs) experience high rates of anaemia, in which the highest prevalence rates are reported in Central and West Africa (56\%), South Asia $(52 \%)$ and East Africa $(36 \%){ }^{2}$ Similarly, a large proportion of non-pregnant women were reportedly anaemic in West and Central Africa (48\%), South Asia (47\%) and East Africa $(28 \%) .^{2}$ Anaemia can have negative effects on a woman's health including maternal mortality and severe morbidity, ${ }^{3}$ depression, ${ }^{45}$ raised blood pressure,${ }^{67}$ as well as negative influences on the infant including low birth weight and preterm birth. ${ }^{8}$ Thus, anaemia remains one of the global health priority areas at the global level, particularly in resource-limited settings. ${ }^{9}$ Reducing anaemia is considered as an essential part of improving the health of women, and the WHO has set a global target of achieving $50 \%$ reduction of anaemia among women of reproductive age by $2025 .^{10}$ 


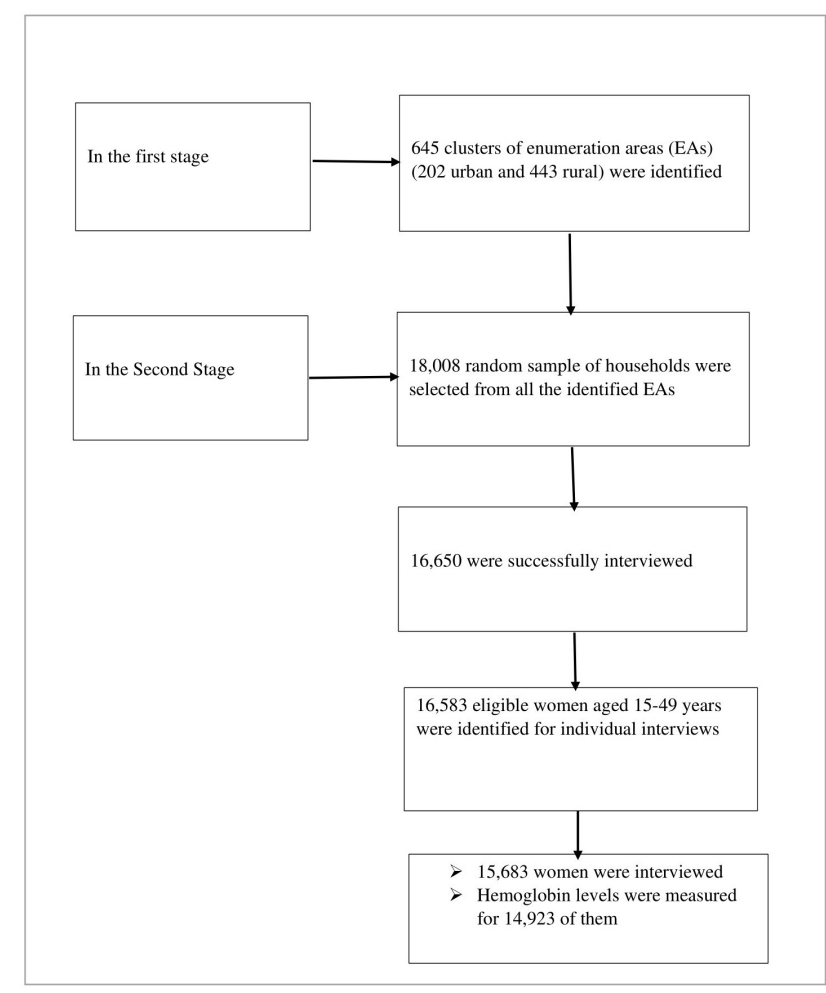

Figure 1 Selection of the sample in the 2016 EDHS. EDHS, Ethiopian Demographic Health Survey.

Anaemia is also a common problem in Ethiopia; the recent Ethiopian Demographic Health Survey (EDHS 2016) reported $29 \%$ prevalence of anaemia among pregnant women and $24 \%$ among women of reproductive age; these prevalence rate ranging from $16 \%$ to $59 \%$ across different parts of the country. ${ }^{11}$ Likewise, in several pocket studies from different parts of the country, researchers reported varied anaemia prevalence rates among pregnant women, which ranged from $17 \%$ in the north, ${ }^{12} 32 \%$ in the south ${ }^{13}$ and up to $44 \%{ }^{14}$ and $57 \%{ }^{15}$ in the eastern part of Ethiopia. Similarly, in different studies, there was reported to be a $16 \%{ }^{16}$ prevalence of anaemia among non-pregnant women and $29 \%^{17}$ and $30 \%{ }^{18}$ among women of reproductive age.

There are a number of different factors contributing to the burden of anaemia, with iron deficiency the main cause of the disease. ${ }^{20}$ Other micronutrients (vitamin $A$, vitamin $B_{12}$ and folate), chronic bleeding, acute or chronic infections and parasitic infections (hookworm and malaria) are also known to cause anaemia. ${ }^{16} 21-23$ Based on the geographic distribution and disease burden in LMIC, about half of anaemia cases are attributable to a deficiency of iron and the remainder may be due to diseases like parasitic infections, malaria and HIV. ${ }^{24}$ A recent systematic review revealed that the proportion of anaemia caused by iron deficiency was below $50 \%$ in LMIC, with regional variations, poor sanitary conditions and subsequent increased occurrence of infections also contributing to anaemia. ${ }^{25}$
In Ethiopia, varied prevalence rates of anaemia among women have been observed with different factors across different parts of the country. ${ }^{12}{ }^{15}$ For instance, large family size, low education status, rural residence, hookworm infestation and HIV infection were identified as factors contributing to anaemia in northern Ethiopia, ${ }^{126}$ while in studies from the eastern area, it was reported that multigravidas, third trimester of pregnancy and intestinal infestation were factors contributing to anaemia during pregnancy. ${ }^{142}$ The variation in rates of anaemia among women in Ethiopia might be due to the presence of diverse contextual and geographically variable factors including diet and the incidence of communicable diseases. ${ }^{9}$

To date, spatial analyses have not been conducted to identify areas with hotspots (high prevalence rates) of anaemia among reproductive age women in Ethiopia. Assessing the geographic distributions of anaemia and the impact of risk factors on disease prevalence by area is important to prioritise and design targeted prevention and intervention programmes to address anaemia in women. ${ }^{28}$ In addition, the burden of anaemia has been used as a measurable indicator of soil-transmitted helminthiasis, so understanding the geographical distribution of anaemia can help target prevention and control mechanisms for parasitic infections such as these. ${ }^{29}$

Thus, the aims of this study were to assess the spatial distribution and determinant factors of anaemia among women of reproductive age women in Ethiopia.

\section{METHODS}

\section{Patient and public involvement}

This study used a publicly available data set (EDHS 2016); therefore, there were no patients or members of the public involved.

\section{Study design and setting}

An in-depth analysis of the EDHS 2016 data was undertaken for this study. EDHS 2016 was a population-based cross-sectional study conducted across the country. It is the fourth national survey conducted in all parts of Ethiopia (in nine regional states [Tigray, Afar, Amhara, Oromia, Somali, Benishangul-Gumuz, Southern Nations, Nationalities and Peoples' Region [SNNPR], Gambella and Harari] and two city administrations [Addis Ababa and Dire Dawa]). ${ }^{11}$ In Ethiopia, the states are administratively further subdivided into zones, zones into Woredas and Woredas further into the lowest unit called Kebeles.

\section{Sampling and data measurements}

In the 2016 EDHS, stratified and cluster multistage sampling was used, and it was intended to be representative at the regional and national level in terms of appropriate demographic and health indicators. In the first stage, 645 clusters of enumeration areas (EAs) (202 urban and 443 rural) were identified using probability proportional to the size of EAs. In the second stage, a random sample of 18008 households were selected from all the 
identified EAs. A total of 15683 women aged 15-49 years were interviewed, and haemoglobin levels were measured for 14923 of them $^{11}$ (figure 1). Data collection took place from 18 January 2016 to 27 June 2016.

The sample size for EDHS was determined based on the multistage sampling procedure, taking into consideration the sampling variation. SEs were computed using the Taylor linearisation method. The design effect, which is the ratio between the SE with the given sample design and the SE that would result if a simple random sample had been used, was determined. ${ }^{11}$

Haemoglobin levels of the women were measured using HemoCue, which is the standard test used in the EDHS 2016, and all haemoglobin values were adjusted for both altitude and smoking status. ${ }^{11}$ Pregnant women with a haemoglobin value $<110 \mathrm{~g} / \mathrm{L}$ and non-pregnant women with a haemoglobin value $<120 \mathrm{~g} / \mathrm{L}$ were considered anaemic. ${ }^{1}$ Similarly, anaemia was classified according to its severity as severe (haemoglobin value $<70 \mathrm{~g} / \mathrm{L}$ ), moderate $(70-99 \mathrm{~g} / \mathrm{L})$ in all women and mild $(100.0-109 \mathrm{~g} / \mathrm{L})$ in pregnant women and non-pregnant women $(100-119 \mathrm{~g} / \mathrm{L}) .{ }^{1}$

\section{Explanatory variables (determinant factors)}

Both individual-level and community-level factors were used. The individual-level and community-level factors included in this study are presented in online supplementary table 1 with their definition and coding. The variables were selected based on the literature review for factors affecting anaemia, ${ }^{12} 142627$ and sociodemographic, maternal as well as community level factors were identified as important factors for the occurrence of anaemia. Therefore, all the available variables in the data set were included for the analysis. Individual factors included age, religion, marital status, educational status, body mass index, birth interval, use of contraceptives, wealth index, family size, iron-folate intake and gravidity of women, while the community level factors were residence (urban and rural), region, water source and latrine facility type. Community-level measures could also be driven by aggregating individual level variables, for example, the proportion of women in the community who are in the top quantile of wealth index and proportion of women in the community who have clean water access. Community-level factors describe the group of populations living in similar settings.

The assumption of independence of observation has been taken as a basis to determine which variables are analysed at individual and community level. If the observations at the individual level are independent, variables were treated as individual-level factors. Whereas, if the observations were clustered into higher levels of units and if several women have shared features such as place of residence, types of water source, latrine facility and region that could have the same effect on anaemia among women in the locality, then variables are analysed at the community level.

\section{DATA ANALYSIS}

\section{Spatial analysis}

Spatial analyses were performed using Geoda V.1.8.10 ( geodacenter.github.ib), QGIS V.2.18.0 (qgis.org) and Arch GIS software V.10.1 (arcgis.com), and base files of the administrative regions for Ethiopia were obtained from DIVA (diva-gis.org). The spatial analysis was conducted by joining the occurrence of anaemia (as proportions) with each cluster to the corresponding geospatial location (survey cluster values). The values of Demographic Health Survey data were merged with the geographic poisoning system (GPS) dataset in Geoda software, and these values were imported into the QGIS software. Anaemia proportions were then computed at lower (cluster), zonal and regional levels using QGIS.

The spatial pattern of the rate of anaemia among women of reproductive age was visualised, and a spatially smoothed proportion was obtained through empirical Bayes estimation methods. ${ }^{30}$ The smoothed proportions present clearer patterns, where the problem was most severe. The spatial empirical Bayes 'smooth' estimates technique was able to deal with spatial heterogeneity. The estimation technique guarantees that estimates of neighbouring states are more alike than estimates of states that are further away. ${ }^{31}$

A standardised prevalence rate, or the ratio of the observed prevalence rate to a national prevalence rate, was determined using Geoda software. ${ }^{31}$ Geoda implements this in the form of an excess risk estimate as part of the map. The excess risk rate is the ratio of the observed rate to the average rate computed for all the data. ${ }^{31}$

Furthermore, a spatial analysis was performed to identify the clustering of anaemia in women or hotspot areas (the areas that have higher anaemia prevalence rates compared with the national average) in different regions of Ethiopia. Spatial analysis is an epidemiological method useful to specify geographic areas with high or low rates of disease occurrence and variability over the region or country. ${ }^{32}$ Getis-Ord Gi* statistics was used for this spatial analysis. Local Getis-Ord Gi* statistics ${ }^{33}$ are important to identify the hot and cold spot areas for anaemia in reproductive age women using GPS latitude and longitude coordinate readings that were taken at the nearest community centre for EAs or EDHS 2016 clusters. ${ }^{11}$ An anaemia hotspot refers to the occurrence of high prevalence rates of anaemia clustered together on the map, whereas cold spots refers to the occurrence of low prevalence rates of anaemia clustered together on the map. ${ }^{33}$

A local Getis-Ord G-statistic tool in ArcGIS was used to calculate the spatial variability of high and low prevalence rates of anaemia among women of reproductive age. An autocorrelation can be classified into positive and negative correlations through the local Getis-Ord G statistics. ${ }^{33}$ Positive autocorrelation occurs when similar values clustered together on a map (high rates surrounded by nearby high rates or low rates surrounded by nearby low rates). Negative autocorrelation indicates different values clustered together on a map, that is, high values surrounded 
by nearby low values or low values surrounded by nearby high values. Statistical significance of autocorrelation was determined by z-scores and $p$ value with a $95 \%$ level of confidence. The distribution and variations of anaemia prevalence rates among women across the country were displayed on the map.

\section{Statistical analysis}

The descriptive statistical analysis was performed using SPSS software V.24.0 (www.spss.com) by complex sample analysis. Frequencies, percentage and SD were used for the descriptive analysis. Since some regions with small populations were oversampled, while others with large population were under-represented, the weighted frequencies and percentages (based on population size of each region) were computed as a correction. The detailed weighting procedure was described in EDHS 2016 report. $^{11}$ The mean and SD were computed for blood haemoglobin level. The mean haemoglobin value was also compared across different independent categorical variables using one-way analysis of variance or independent t-test.

The multivariable multilevel logistic regression model was used to determine the effect of different factors on anaemia among women. The analysis was performed by using SAS V.9.4 software (www.sas.com) using Proc Glimmix with Laplace's method. For this multilevel analysis, four models were constructed. The first model was constructed without independent variables to assess the effect of community variation on anaemia among women. Individual-level factors were incorporated in the second model. In the third model, community-level factors were included. Finally, both individual-level and community-level factors were included in the fourth model.

The results of fixed effects were presented as OR with 95\% CIs. An adjusted OR (AOR) with 95\% CIs was computed to identify the independent factors of anaemia among women, and a $p$ value $<0.05$ was used as a measure of statistical significance. A muliticollinearity test was done in order to rule out a significant correlation between variables. If the values of variance inflation factor (VIF) was lower than 10, then the collinearity problem was considered as less likely. The random effects (variation of effects) were measured by intracluster correlation coefficient (ICC) (variance partition coefficient), ${ }^{34}$ percentage change in variance $(\mathrm{PCV})^{35}$ and median $\mathrm{OR}$ (MOR),${ }^{346}$ which measure the variability between clusters in the multilevel models. ICC explains the cluster variability, while MOR can quantify unexplained cluster variability (heterogeneity). MOR translates cluster variance into OR scale. In the multilevel model, PCV can measure the total variation due to factors at the community and individual level. ${ }^{35}$ The ICC, PCV and MOR were determined using the estimated variance of clusters using the following formula ${ }^{3435}$ :

$$
\begin{aligned}
& \text { ICC }=\frac{V}{\left(V+\frac{\pi^{2}}{3}\right)} \text { MOR }=\exp \sqrt{2 \times V \times 0.6745} \sim \exp \\
& (0.95 \sqrt{V})]
\end{aligned}
$$

where $V$ is the estimated variance of clusters and

$$
\mathrm{PCV}=\frac{\left(V_{A}-V_{B}\right)}{V_{B}} \times 100
$$

where $V_{A}=$ variance of the initial model; $V_{B}=$ variance of the model with more terms.

The multilevel analysis model is one of the analysis methods that can correctly handle the correlated data. ${ }^{37}$ A multilevel model evaluates how factors at different levels affect the dependent variable. A multilevel model provides correct parameter estimates by correcting the biases introduced from clustering by producing correct SEs, thus producing correct CI, and significance tests. ${ }^{37}$

\section{Ethical consideration}

Publicly available EDHS 2016 data were used for this study. Informed consent was taken from each participant, and all identifiers were removed.

\section{RESULTS}

\section{Sociodemographic characteristics}

The data on 14923 women were included in this analysis, including 642 clusters nested in 11 regions. The descriptive statistics of the study participants are presented in table 1 . The mean $( \pm \mathrm{SD})$ age of the respondents was 28.2 years $( \pm 9.2$ years). The majority of participants lived in a rural area $(78 \%)$. Nearly two-thirds $(66 \%)$ of participants were married or living with a partner. Almost half $(48 \%)$ of the women had no formal education, and around $43 \%$ were followers of the Orthodox Tewahdo Christian religion. Only $18 \%$ of the households had access to a piped water source for drinking, and $15 \%$ had access to an improved latrine facility. Nearly one-third $(\mathrm{n}=4657$; $31.2 \%$ ) of women were breast feeding at the time of the survey (table 1). The average haemoglobin level among lactating mothers was $126 \mathrm{~g} / \mathrm{L}( \pm 17 \mathrm{~g} / \mathrm{L})$, and about $28.3 \%$ (95\% CI $25.7 \%$ to $31.0 \%$ ) of these women were anaemic.

\section{Prevalence rate of anaemia among women}

Among all respondents, the mean $( \pm \mathrm{SD})$ blood haemoglobin level (adjusted for altitude) was $128 \mathrm{~g} / \mathrm{L}$ $( \pm 17 \mathrm{~g} / \mathrm{L})$. The overall prevalence of anaemia among women of reproductive age across the country was $23.6 \%$ (95\% CI 22.0 to 25.3). The prevalence of mild, moderate and severe anaemia among all women of reproductive age were $17.8 \%$ (95\% CI 16.7 to 19 ), $5.0 \%$ (95\% CI 4.3 to 5.8 ) and $0.8 \%$ (95\% CI 0.5 to 1.2 ), respectively. There was regional variation in anaemia prevalence among women of reproductive age $(p=0.0001)$ and higher prevalence rates observed in Afar, Somali, Gambella, Dire Dawa and Oromia regions. Lower prevalence of anaemia was observed in Addis Ababa, Tigray and Amhara regions. Rural areas had a higher prevalence, 25.4 (95\% CI 23.5 to $27.4)$ of anaemia in women than urban areas, $17.0(95 \%$ CI 14.4 to 20.0) $(\mathrm{p}=0.0001)$. The highest proportion of anaemia among women were found in Somali Regional 
Table 1 Sociodemographic and other health-related characteristics of study participants included in the analysis, EDHS $2016(n=14923)$

\begin{tabular}{ccc}
\hline Variables & $\begin{array}{l}\text { Weighted } \\
\text { frequency }\end{array}$ & $\begin{array}{l}\text { Weighted } \\
\text { per cent }\end{array}$ \\
\hline Age (years) & & \\
$15-19$ & 3165 & 21.2 \\
$20-29$ & 5467 & 36.6 \\
$30-39$ & 4078 & 27.3 \\
$40-49$ & 2213 & 14.8
\end{tabular}

Place of residence

$\begin{array}{lrr}\text { Urban } & 3169 & 21.2 \\ \text { Rural } & 11754 & 78.8\end{array}$

\section{Educational status}

$\begin{array}{lrr}\text { No education } & 7215 & 48.3 \\ \text { Primary } & 5244 & 35.1 \\ \text { Secondary } & 1676 & 11.2 \\ \text { Higher } & 789 & 5.3\end{array}$

Marital status

$\begin{array}{lrr}\text { Single } & 3758 & 25.2 \\ \text { Married } & 9800 & 65.7 \\ \text { Divorced/widowed/separated } & 1365 & 9.1\end{array}$

Religion

\begin{tabular}{|lrr|}
\hline Orthodox & 6447 & 43.2 \\
\hline Protestant & 3514 & 23.5 \\
\hline Muslim & 4645 & 31.1 \\
\hline Other & 317 & 2.1 \\
\hline Region & & \\
\hline Tigray & 1073 & 7.2 \\
\hline Afar & 119 & 0.8 \\
\hline Amhara & 3645 & 24.4 \\
\hline Oromia & 5422 & 36.3 \\
\hline Somali & 417 & 2.8 \\
\hline Benishangul-Gumuz & 146 & 1.0 \\
\hline SNNPR & 3124 & 20.9 \\
\hline Gambella & 42 & 0.3 \\
\hline Harari & 32 & 0.2 \\
\hline Addis Ababa & 825 & 5.5 \\
\hline Dire Dawa & 77 & 0.5 \\
\hline Wealth index & & \\
\hline Poorest & 2519 & 16.9 \\
\hline Poorer & 2717 & 18.2 \\
\hline Middle & 2891 & 19.4 \\
\hline Richer & 2979 & 20.0 \\
\hline Richest & 3816 & 25.6 \\
\hline BMl 18.5 & & \\
\hline 18.5-24.9 & 9740 & 7.4 \\
\hline P25 & & Continued \\
\hline
\end{tabular}

Table 1 Continued

\begin{tabular}{lcc}
\hline Variables & $\begin{array}{l}\text { Weighted } \\
\text { frequency }\end{array}$ & $\begin{array}{l}\text { Weighted } \\
\text { per cent }\end{array}$ \\
\hline $\begin{array}{l}\text { Birth interval } \\
\quad<24 \text { months }\end{array}$ & 1415 & 18.3 \\
$\quad>=24$ months & 6305 & 81.7 \\
\hline $\begin{array}{l}\text { Current use of contraceptives } \\
\text { Yes }\end{array}$ & 1088 & 7.3 \\
\hline No & 13835 & 92.7 \\
$\begin{array}{l}\text { Iron folate intake during } \\
\text { pregnancy (n=7328) }\end{array}$ & & \\
\hline $\begin{array}{l}\text { Yes } \\
\text { No/don't know }\end{array}$ & 3108 & 42.4 \\
\hline
\end{tabular}

Gravidity of women (children ever born)

$\begin{array}{lll}0 & 4745 & 31.8 \\ 1-3 & 4715 & 31.6 \\ 4+ & 5464 & 36.6\end{array}$

Children ever born in the

preceding 5 years

$\begin{array}{lll}0 & 7595 & 50.9 \\ 1 & 4475 & 30.0 \\ 2+ & 2852 & 19.1\end{array}$

Currently breast feeding

$\begin{array}{lrr}\text { Yes } & 4657 & 31.2 \\ \text { No } & 10266 & 68.8\end{array}$

\section{Currently pregnant}

$\begin{array}{rrr}\text { Yes } & 1088 & 7.3 \\ \text { No } & 13835 & 92.7\end{array}$

\section{Smoking}

$\begin{array}{lrr}\text { Yes } & 96 & 0.6 \\ \text { No } & 14827 & 99.4\end{array}$

Birth in the last year

$\begin{array}{lrr}0 & 12474 & 83.6 \\ 1-2 & 2449 & 16.4\end{array}$

HIV test

$\begin{array}{lrr}\text { Positive } & 187 & 1.3 \\ \text { Negative } & 14724 & 98.7 \\ \text { Water source } & & \\ \text { Piped water } & 2646 & 17.7 \\ \text { Other improved } & 6926 & 46.4 \\ \text { Unimproved } & 5351 & 35.9 \\ \text { Latrine facility type } & & \\ \text { Improved toilet } & 2231 & 14.9 \\ \text { Unimproved toilet } & 7877 & 52.8 \\ \text { Open defecation } & 4414 & 29.6 \\ \text { Other } & 401 & 2.7\end{array}$

Anaemia status

$\begin{array}{lll}\text { Anaemic } & 3527 & 23.6\end{array}$

Continued 


\begin{tabular}{|c|c|c|}
\hline Variables & $\begin{array}{l}\text { Weighted } \\
\text { frequency }\end{array}$ & $\begin{array}{l}\text { Weighted } \\
\text { per cent }\end{array}$ \\
\hline Non-anaemic & 11396 & 76.4 \\
\hline $\begin{array}{l}\text { Proportion of women in the } \\
\text { community who have clean water } \\
\text { source, } m(S E)\end{array}$ & 64.1 (33.6) & \\
\hline $\begin{array}{l}\text { Proportion of women in the } \\
\text { community who have unimproved } \\
\text { latrine facility; } m(S E)\end{array}$ & $85.1(25.0)$ & \\
\hline $\begin{array}{l}\text { Proportion of women in the } \\
\text { community who are in lowest } \\
\text { quantile of wealth index, m (SE) }\end{array}$ & $35.1(30.0)$ & \\
\hline $\begin{array}{l}\text { Percentage of unimproved water } \\
\text { per cluster, } \mathrm{m}(\mathrm{SE})\end{array}$ & 35.9 (33.6) & \\
\hline
\end{tabular}

BMI, bodymass index; EDHS, Ethiopian Demographic Health Survey; m, mean; SNNPR, Southern Nations, Nationalities and Peoples' Region.

States, while the lowest proportions were found in Addis Ababa city administration (table 2).

Around 1088 (7.3\% [95\% CI 6.6 to 8.1]) participants were pregnant at the time of the interview. The mean haemoglobin level among pregnant women was $117 \mathrm{~g} / \mathrm{L}$ $( \pm 18 \mathrm{~g} / \mathrm{L})$ and $29.1 \%$ (95\% CI 24.9 to 33.7$)$ of these women were anaemic. The prevalence of anaemia was higher among pregnant women, $29.1 \%$ (95\% CI $24.9 \%$ to $33.7 \%)$ than non-pregnant women, $23.2 \%$ $(95 \%$ CI $21.6 \%$ to $24.9 \%)(p=0.003)$ (table 2$)$. The mean haemoglobin value of women in their second and third trimester was significantly lower compared with women in their first trimester $(\mathrm{p}=0.001)$. The mean haemoglobin levels in pregnant women who had less than a 24-month birth interval (for their most recent birth) was significantly lower compared with women who had a birth interval of less than or equal to 24 months $(p=0.0001)$. Similarly, receiving iron folate supplements during pregnancy improved the mean haemoglobin values in pregnant women (table 3 ).

\section{Determinant factors of anaemia among women of reproductive age \\ Multilevel analysis (fixed effect analysis)}

The results of multilevel logistic regression for the individual-level and community-level variables are presented in table 4. In the full model in which all individual-level and community-level factors are included, residence, education, religion, wealth index, pregnancy and breastfeeding status, gravidity of women and lack of availability of an improved latrine were factors significantly associated with anaemia in women. The results of the muliticollinearity test indicated that no collinearity problem existed, since the VIF value of all variables is lower than 10 (supplementary table 2).

\section{Individual factors}

The average haemoglobin value was significantly different across age groups $(\mathrm{p}=0.0001)$. The highest mean haemoglobin level, $130 \mathrm{~g} / \mathrm{L}$, was observed in the youngest (15-19years) age group, while the lowest mean haemoglobin level, $127 \mathrm{~g} / \mathrm{L}$, in the age group of 30-34years. The general pattern indicated roughly linear decline among women aged 15-34years (figure 2). Women aged 40-49years old were $25 \%$ less likely to be anaemic compared with women in the youngest age group (15-19years old) (AOR=0.75; $95 \%$ CI 0.64 to 0.96 ). Those women with limited education were 1.37 times more likely to be anaemic than women who completed higher education (AOR=1.37; 95\% CI 1.102 to 1.72). The odds of anaemia increased by $29 \%$ (AOR $=1.29$; $95 \%$ CI 1.014 to 1.60 ) when comparing the poorest to the richest women. The odds of anaemia were higher in women who were pregnant $(\mathrm{AOR}=1.28 ; 95 \% \mathrm{CI} 1.10$ to 1.51) compared with those who were not pregnant. Women who were currently breast feeding were $9 \% \quad(\mathrm{AOR}=1.09$; 95\% CI 1.025 to 1.28 ) more likely to be anaemic. The odds of anaemia were $39 \%$ higher among mothers who had given birth to four or more children (AOR=1.39; $95 \%$ CI 1.13 to $1.69)$. Women who gave birth to two or more children in the preceding 5 years of the survey were at higher risk of having anaemia (AOR=1.31; 95\% CI 1.09 to 1.57 ). In this study, women who were HIV positive had a twofold increased odds of having anaemia compared with women classified as HIV negative $(\mathrm{AOR}=2.11 ; 95 \% \mathrm{CI} 1.59$ to 2.79$)$ (table 4$)$.

\section{Community-level factors}

Living in a rural area was associated with a $29 \%$ higher odds of anaemia among women of reproductive age than women who were urban residents (AOR $=1.29 ; 95 \%$ CI 1.02 to 1.63$)$. Women from households without access to a latrine had $18 \%$ higher odds of anaemia compared with women from households that had an improved latrine facility (AOR=1.18; $95 \%$ CI 1.01 to 1.39 ). Higher odds of anaemia were observed in Somali regional state (AOR $=2.16 ; 95 \%$ CI 1.58 to 2.90 ) compared with Dire Dawa. However, the odds of anaemia among women were lower in Gambella, Addis Ababa, Amhara and Oromia region compared with Dire Dawa (table 4).

\section{Multilevel analysis (random effect analysis)}

The results of the random effects model is shown in table 4 . Prevalence rate of anaemia varied across communities $\left(\mathrm{t}^{2}=0.88, \mathrm{p}=<0.0001\right)$. In other words, the anaemia prevalence rate was not similarly distributed across the communities. About $21 \%$ of the variance in the odds of anaemia in women could be attributed to community-level factors, as calculated by the ICC based on estimated intercept component variance. After adjusting for individual-level and community-level factors, the variation in anaemia across communities remained statistically significant. About 16\% of the odds of anaemia variation across communities was observed in the full model (model 4) (table 4).

Moreover, the MOR indicated that anaemia was attributed to community-level factors. The MOR for anaemia was 2.44 in the empty model (model 1); this showed that there was variation between communities (clustering) since MOR was 2.4 times higher than the reference $(M O R=1)$. The 
Table 2 The variation of anaemia prevalence rates across different regions and different sociodemographic characteristics of women in Ethiopia, 2016

\begin{tabular}{|c|c|c|c|c|}
\hline \multirow[b]{2}{*}{ Variables } & \multicolumn{2}{|c|}{ Weighted frequency } & \multirow{2}{*}{$\begin{array}{l}\text { Weighted proportion of } \\
\text { anaemia }(95 \% \mathrm{Cl})\end{array}$} & \multirow{2}{*}{ P value } \\
\hline & Anaemic & Non-anaemic & & \\
\hline \multicolumn{5}{|l|}{ Place of residence } \\
\hline Rural & 2989 & 8766 & 25.4 (23.5 to 27.4$)$ & \\
\hline \multicolumn{5}{|l|}{ Region } \\
\hline Afar & 53 & 66 & 44.7 (39.9 to 49.6$)$ & \\
\hline Amhara & 627 & 3019 & 17.2 (14.9 to 19.7$)$ & \\
\hline Oromia & 1480 & 3942 & 27.2 (23.8 to 31.1$)$ & \\
\hline Somali & 248 & 169 & 59.5 (55.2 to 63.7$)$ & \\
\hline Benishangul-Gumuz & 28 & 118 & 19.2 (16.1 to 22.7$)$ & \\
\hline Harari & 9 & 23 & 27.7 (23.7 to 32.1$)$ & \\
\hline Addis Ababa & 132 & 693 & 16 (13.5 to 18.8$)$ & \\
\hline Dire Dawa & 23 & 54 & 30 (25.8 to 34.8$)$ & \\
\hline \multicolumn{5}{|l|}{ Education status } \\
\hline No education & 2002 & 5212 & 27.8 (25.4 to 30.2 ) & 0.0001 \\
\hline Primary & 1136 & 4108 & 21.7 (19.8 to 23.7 ) & \\
\hline Secondary & 297 & 1378 & 17.8 (14.9 to 21.0$)$ & \\
\hline Higher & 91 & 697 & 11.5 (8.2 to 16.0$)$ & \\
\hline \multicolumn{5}{|l|}{ Wealth index } \\
\hline Yes & 317 & 771 & 29.1 (24.9 to 33.7 ) & 0.003 \\
\hline No & 3210 & 10625 & 23.2 (21.6 to 24.9$)$ & \\
\hline \multicolumn{5}{|l|}{ Currently breast feeding } \\
\hline Yes & 1317 & 3340 & 28.3 (25.7 to 31.0 ) & 0.0001 \\
\hline No & 2210 & 8055 & 21.5 (20.0 to 23.2 ) & \\
\hline Total & 3527 & 11396 & 23.6 (22.0 to 25.3$)$ & \\
\hline
\end{tabular}

SNNPR, Southern Nations, Nationalities and Peoples' Region.

unexplained community variation in anaemia decreased to MOR of 2.1 when all factors were added to the null model (empty model). This indicates that when all factors are included, the effect of clustering is still statistically significant in the full model (table 4).

\section{Spatial data analysis}

Figure 3 displays the empirical Bayes smoothed proportion estimate of anaemia among women across regions in Ethiopia. A severe anaemia prevalence rate $(\geq 40 \%)$ among women of reproductive age was observed in Afar and Somali Regional States. Likewise, a moderate anaemia prevalence rate $(20 \%-40 \%)$ occurred in Oromia, Gambella, SNNPR, Harari and Dire Dawa Regional States. Whereas, a mild anaemia prevalence rate $(<20 \%)$ was observed in Tigray and Amhara Regional Sates and Addis Ababa.

Similarly, the standardised prevalence ratio by regions (standardised to the national average prevalence of 
Table 3 Haemoglobin level among pregnant women in Ethiopia, 2016

\begin{tabular}{|c|c|c|c|}
\hline Variables & Number & $\begin{array}{l}\text { Haemoglobin level (g/L) } \\
\text { (mean(SD)) }\end{array}$ & $\begin{array}{l}\text { P values of ANOVA or } \\
\text { independent } t \text {-test }\end{array}$ \\
\hline Total Children ever born & 1088 & & 0.0001 \\
\hline 0 & 213 & $121(17)$ & \\
\hline $1-3$ & 484 & $117(18)$ & \\
\hline $4+$ & 390 & $115(18)$ & \\
\hline Pregnancy stage & 1088 & & 0.0001 \\
\hline 1st trimester & 226 & $124(17)$ & \\
\hline 2nd trimester & 433 & $116(16)$ & \\
\hline 3rd trimester & 429 & $115(19)$ & \\
\hline Children ever born in last 5 years & 1088 & & 0.0001 \\
\hline 0 & 339 & $121(17)$ & \\
\hline 1 & 484 & $117(18)$ & \\
\hline $2+$ & 265 & $114(19)$ & \\
\hline Fe-Fol supplementation & 749 & & 0.018 \\
\hline Yes & 251 & $118(15)$ & \\
\hline No & 498 & $115(19)$ & \\
\hline Birth interval & 702 & & 0.0001 \\
\hline$<24$ months & 206 & $112(20)$ & \\
\hline$>=24$ months & 497 & $119(15)$ & \\
\hline
\end{tabular}

ANOVA, analysis of variance; Fe-Fol, ironfolate.

$23.6 \%$ ), ranging from 0.63 to 2.39 , was displayed on the map (figure 4). A higher prevalence ratio of anaemia was observed in Somali (2.39), Afar (1.8) Oromia (1.17), Dire Dawa (1.15) and Gambella (1.12) regional states (figure 4), whereas a lower prevalence ratio of anaemia occurred in other regional states: Addis Ababa (0.64), Amhara (0.76), Benishangul-Gumuz (0.79), SNNPR (0.96) and Tigray (0.85) (figure 4).

Figure 5 displays the smoothed anaemia prevalence rates at zonal level where higher anaemia rates were observed in all zones in Afar and Somali regions, as well as in some zones in Oromia. Likewise, the higher standardised ratio of anaemia was observed in all zones in Afar and Somali regions as well as in some zones in Oromia (figure 6).

The spatial distributions of anaemia among women at the lower level (cluster level) is displayed in figure 7 . The spatial investigation at the cluster level indicated that statistically high hotspots of anaemia were observed in the eastern (Somali, Dire Dawa and Harari regions) and in north-eastern (Afar) parts of the country, while cold spots of anaemia were observed in the northern (Tigray and Amhara), central (Addis Ababa and Oromia) and western (Benishangul-Gumuz and Gambella) parts of the country (figure 7).

\section{DISCUSSION}

Approximately a quarter of women of reproductive age were anaemic in the current study, indicating that anaemia is a moderate public health problem at the national level in Ethiopia. ${ }^{1}$ However, geographic differences demonstrated that anaemia is a serious public health problem in 5 of the 11 Ethiopian states. A higher proportion of anaemia cases was observed in the eastern and north-eastern parts of the country, which are less developed compared with other Ethiopian states in terms of economy, gender, healthcare facility and food availability. ${ }^{38}$ The geographical difference of anaemia across the regional states might be attributable to the regional variation of food consumption preferences, ${ }^{39} 40$ the occurrence of communicable disease ${ }^{41}$ and differences in availability of healthcare facilities. ${ }^{42}$ In addition, lack of clean water and unimproved latrine facilities would increase the occurrence of soil transmitted infection ${ }^{43}$ which, in turn, could lead to anaemia, ${ }^{44}$ which might explain some of the observed geographical differences.

According to the final model, both individual-level and community-level factors were responsible for about $43 \%$ of the disparity of anaemia prevalence rates among women of reproductive age in Ethiopia. After adjusting for all factors in the model, the likelihood of having anaemia was higher among those of younger age, with lower levels of education, living in rural areas, in the lowest wealth quantile, who were currently pregnant or breast feeding, with high gravidity, who had given birth in the year prior to the survey and who were without access to an improved latrine facility.

Women aged 40-49years had a lower likelihood of being anaemic compared with women aged between 
Table 4 Multivariable multilevel logistic regression analysis for determinant factors associated with anaemia among Ethiopian women, 2016

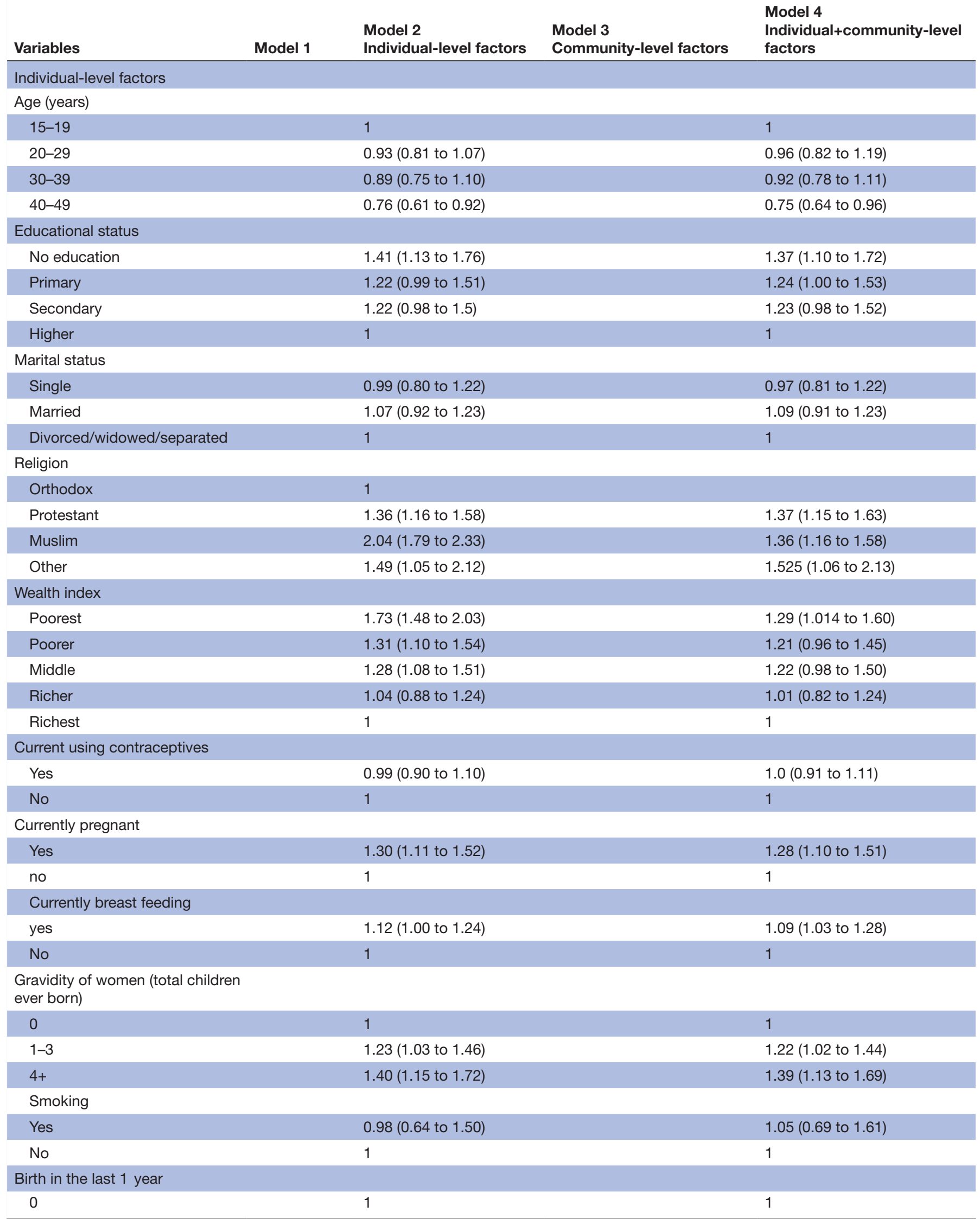

Continued 
Table 4 Continued

\begin{tabular}{|c|c|c|c|c|}
\hline Variables & Model 1 & $\begin{array}{l}\text { Model } 2 \\
\text { Individual-level factors }\end{array}$ & $\begin{array}{l}\text { Model } 3 \\
\text { Community-level factors }\end{array}$ & $\begin{array}{l}\text { Model } 4 \\
\text { Individual+community-level } \\
\text { factors }\end{array}$ \\
\hline $1-2$ & & $1.20(1.05$ to 1.37$)$ & & 1.15 (1.01 to 1.32$)$ \\
\hline
\end{tabular}

Children ever born in preceding

5 years

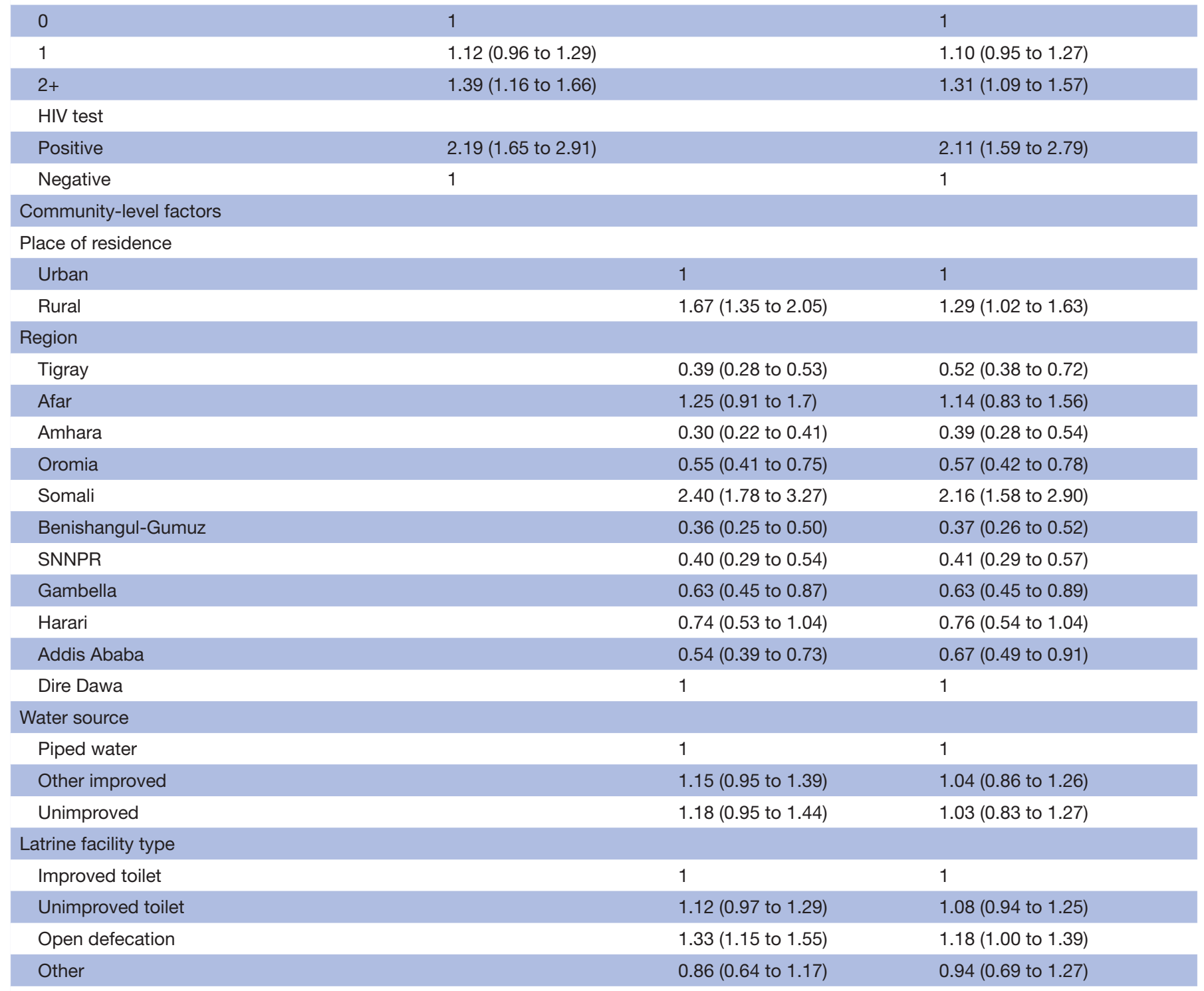

Random effects (effect of

variation / measure of variation for anaemia)

$\begin{array}{lllll}\text { Community level variance (SE) } & 0.888(0.07) & 0.46(0.05) & 0.32(0.04) & 0.31(0.035) \\ \text { P value } & 0.001 & 0.001 & 0.001 & 0.001 \\ \text { DIC (-2log likelihood) } & 7926.056 & 7749.25 & 7720.74 & 7613.56 \\ \text { ICC (\%) } & 21.25 & 16.1 & 18.3 & 15.86 \\ \text { Explained variation - PCV (\%) } & \text { Reference } & 40.95 & 21.0 & 43.1 \\ \text { MOR } & 2.44 & 2.13 & 2.3 & 2.1\end{array}$

Note: Model 1=empty model (without the predictors); model 2=adjusted for individual factors; model 3=adjusted for community-level factors; model 4=adjusted for both community-level and individual-level factors.

DIC, deviance information criterion; ICC, intracluster correlation coefficient; MOR, median OR; PCV, percentage change in variance; SNNPR, Southern Nations, Nationalities and Peoples' Region. 


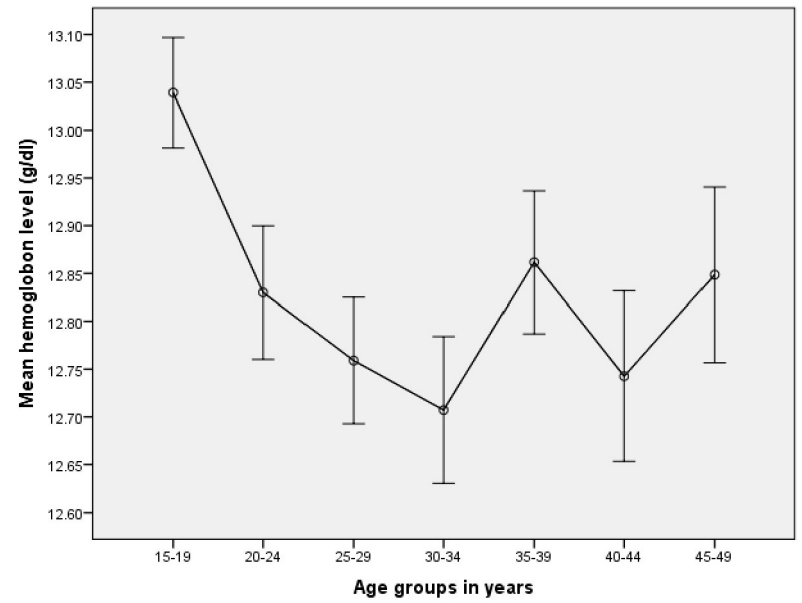

Figure 2 Average haemoglobin value with $95 \% \mathrm{Cl}$ for women of reproductive age at different age groups, Ethiopia, 2016.

15 years and 19 years. This finding is in line with other study findings from Ethiopia ${ }^{16}{ }^{19}$ and Benin. ${ }^{45}$ This could be due to the fact that low fertility rates occurred in this age group. ${ }^{11}{ }^{40-49}$ However, in Iran,${ }^{46}$ it has been reported that women aged 20-24 years were less likely to be anaemic compared with those aged 45-49 years; this might be a result of Iran having a targeted intervention for younger women or women of reproductive age. ${ }^{46}$

In this study, it was found that there is variation of the anaemia rate in terms of education status of the women. A higher proportion of anaemic cases were observed among women with no education. It was found that women who did not have formal education had higher odds of anaemia than those with higher education. This is consistent with other studies conducted in developing countries ${ }^{24}$ including Ethiopia, ${ }^{16}$ Timor-Leste, ${ }^{47}$ Benin $^{45}$ and India ${ }^{48}$ in which it was reported that a low level of education was associated with higher odds

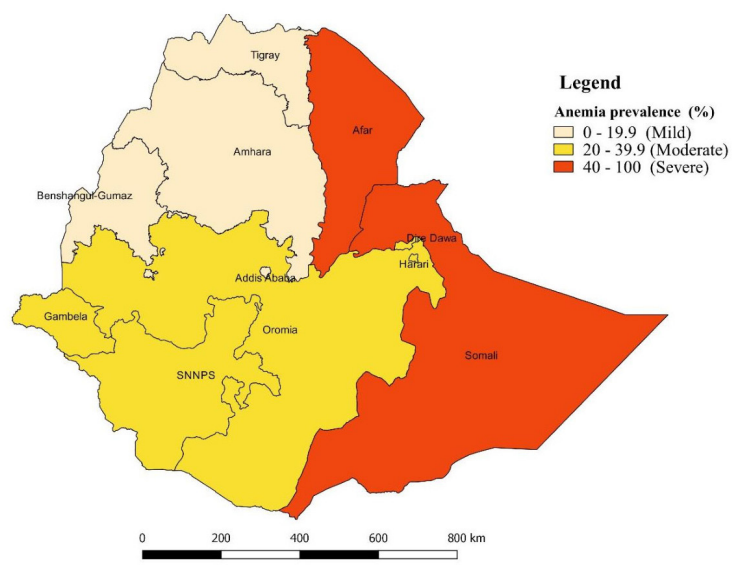

Figure 3 Spatial empirical Bayesian smoothed percentage of anaemia among women of reproductive age across regions, EDHS, 2016. EDHS, Ethiopian Demographic Health Survey.

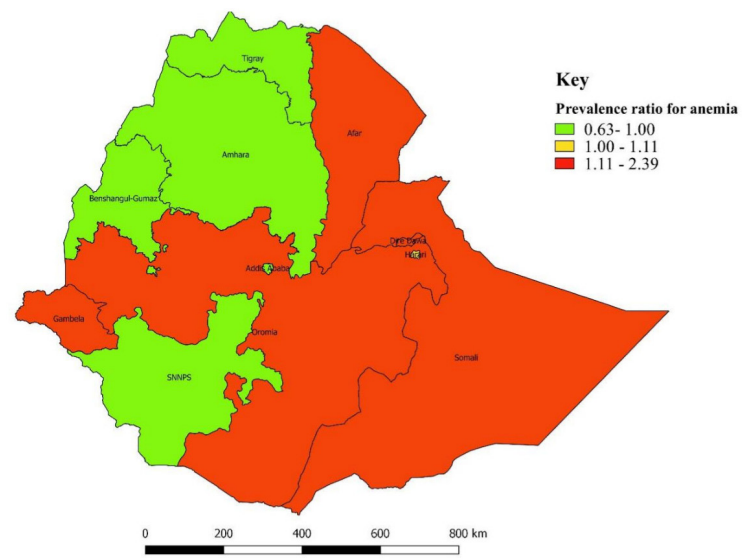

Figure 4 Standardised prevalence ratio for anaemia among women of reproductive age across the regions in Ethiopia (standardised to national prevalence of 23.6\%), EDHS, 2016. EDHS, Ethiopian Demographic Health Survey.

of anaemia among women of reproductive age. Formal education might assist women to obtain knowledge that in turn helps them to follow better lifestyle behaviours like good nutrition and to form better health-seeking habits and hygiene practices that can prevent anaemia among women.

A higher proportion of anaemic cases were observed among women in the poorest wealth quantile. The lowest wealth quantile compared with highest quantile was associated with a higher risk of anaemia. Results of this study show that women who were in the poorest wealth quintile were $30 \%$ more likely to be anaemic than women who belong to the richest quintile; this is in line with the results of other studies conducted in other developing countries $^{24}$ like Benin ${ }^{45}$ and India. ${ }^{49}{ }^{50}$ This might be due to the fact that having a low income would mean having less money to buy nutritious foods or have a balanced $\operatorname{diet}^{5152}$ which, in turn, leads to inadequate nutrient

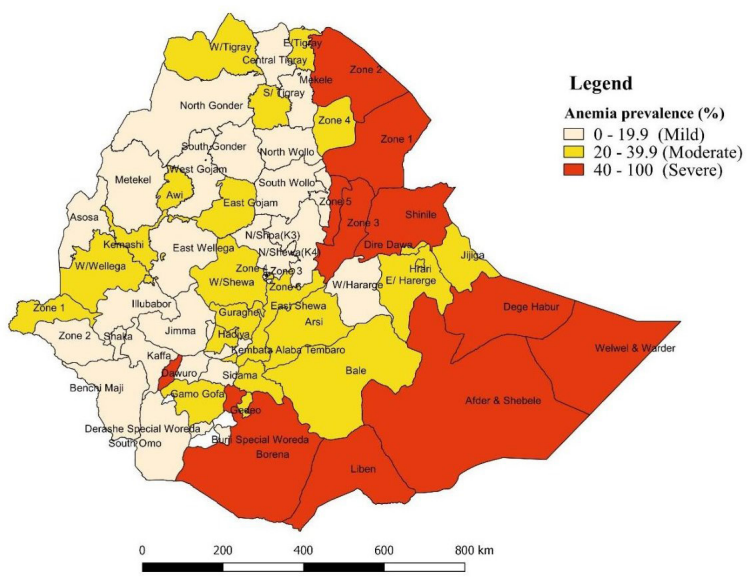

Figure 5 Spatial empirical Bayesian smoothed percentage of anaemia among women of reproductive age across Zones, EDHS, 2016. EDHS, Ethiopian Demographic Health Survey. 


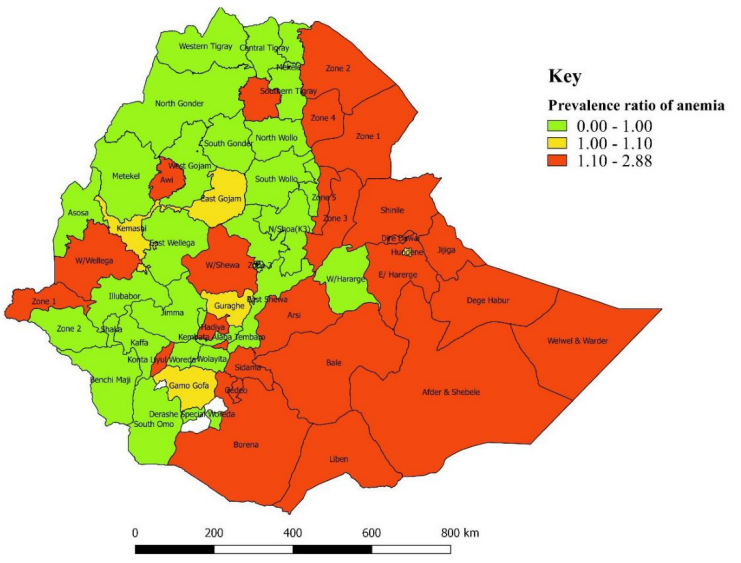

Figure 6 Standardised prevalence ratio for anaemia among women of reproductive age across Zones in Ethiopia (standardised to national prevalence of 23.6\%), EDHS, 2016. EDHS, Ethiopian Demographic Health Survey.

intake and nutritional status. ${ }^{53}$ More than $38 \%$ of the Ethiopian population belongs to the poorer and poorest wealth quintile, which indicates a large percentage of women are at risk for anaemia because of low socioeconomic position. ${ }^{11}$

Lactating mothers were 9\% more likely to have anaemia than non-lactating mothers. Lactating may predispose women to low haemoglobin, which results in anaemia. In a study conducted in India, ${ }^{54}$ a similar finding was reported that lactating mothers were more likely to be anaemic than non-lactating women.

The findings of our study clearly show the role of women's fertility in anaemia. Increased odds of anaemia was associated with high gravidity, births in the past 5 years

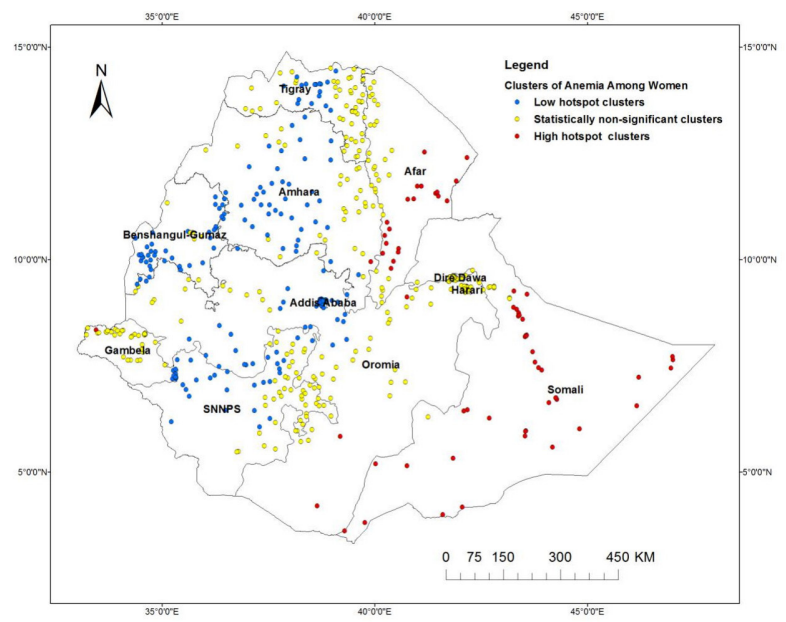

Figure 7 Spatial pattern of hotspots and cold spots of anaemia rate among women of reproductive age at cluster level in Ethiopia, EDHS, 2016. EDHS, Ethiopian Demographic Health Survey. of the survey and having a birth in the last year. Similar studies in Ethiopia, ${ }^{16}$ Iran $^{46}$ and Timor-Leste ${ }^{47}$ also document this association between parity and risk of anaemia. The study results from Pakistan ${ }^{55} 56$ and $\operatorname{Iran}^{46}$ indicate that women with a parity of four or more were found to be at increased risk of anaemia than women with lower parity. This might be explained by the fact that the more the women give birth, the more they are exposed to blood loss which, in turn, results in low haemoglobin levels in the blood. ${ }^{57}$ Similarly, prior births may deplete maternal iron stores due to the increased nutritional demands of pregnancy and puerperal blood loss. ${ }^{58}$ Consequently, emphasis needs to be placed on family planning services. Increased odds of anaemia were observed in women who were HIV positive. In this study, women who were HIV positive had twofold increased odds for anaemia. This could be due to the direct effects of the HIV infection on the bone marrow and depletion of haemoglobin levels in the blood. ${ }^{59}$ Many of the opportunistic infections to which HIV patients are susceptible might also lead to anaemia. ${ }^{59}$

This study revealed there to be a significant difference in the proportion of anaemic cases according to place of residence (urban/rural). The likelihood of having anaemia was higher for rural residents compared with urban residents. This is in agreement with a study conducted in low-income countries in which it was revealed that living in a rural area was a determinant factor for anaemia. ${ }^{24} \mathrm{~A}$ recent report illustrated that more than half of the Ethiopian population had access to unimproved toilet facilities. ${ }^{60}$ Our study findings revealed that women from households with unimproved latrine facilities were more likely to be anaemic than women from households with improved latrine facilities, which is in agreement with other research findings. ${ }^{45} 61$ The possible justification might be that an unimproved latrine facility would expose women to helminthic infections, ${ }^{43}$ which in turn resulted them developing anaemia. $^{44}$

\section{Strengths and limitations}

This study used large population-based data with a large sample size, which is representative of all regions of Ethiopia. Furthermore, a combination of statistical methods (spatial analysis and multilevel logistics analysis) were applied for this study that allows for the understanding of the role of contextual and geographical factors in the occurrence of anaemia among women of reproductive age. Due to the cross-sectional nature of the EDHS data, the cause/effect and temporal relationship could not be established based on these study findings. Similarly, essential factors such as dietary intake and behavioural factors were not available in the EDHS so that it was not possible to incorporate these variables in the analysis. Furthermore, EDHS was a questionnaire-based survey and relied on the memory of the respondents, and as such, recall bias in the results might be a weakness for this study. 


\section{CONCLUSION}

This study indicates that considerable geographic disparities in anaemia prevalence rate occur within Ethiopia. The results of this study revealed that anaemia among women varied across the country; significant anaemia hotspots were observed in the eastern and north-eastern part of the country, while anaemia cold spots were observed in the northern and western parts of the country. About $43 \%$ of the disparity in anaemia occurrence across communities was attributable to both individual-level and community-level factors. The increased occurrence of anaemia among women was associated with individual-level and community-level factors. For women, being of rural residence, having no formal education, being in the poorest wealth index, either currently pregnant or breast feeding and higher gravidity were factors that increased the odds of anaemia at the individual level, whereas lack of a clean water source and access to an unimproved toilet facility were factors significantly associated with anaemia among women.

Accordingly, the prevention of anaemia among women requires multifaceted intervention approaches, for instance, improving the economic and educational status of women and improving the availability of clean water and toilet facilities. Anaemia prevention strategies must be targeted on these identified factors. Priority should be given for those states or areas that have anaemia hotspots. Particularly, any intervention programmes need to be prioritised for pregnant women, women recently giving birth, those with lower levels of education and women living in rural areas. The regions with the greatest numbers of anaemic women (Afar and Somali) should be prioritised, as the burden of anaemia is higher in these areas, with more than $50 \%$ of women being anaemic.

Acknowledgements We would like to thank the Demographic and Health Survey (DHS) programme for allowing the use of Ethiopian Demographic and Health Survey (EDHS) data for this study. We are also very grateful to Dr Ryan 0'Neill for his help in language editing.

Contributors Formulating the research question(s): all authors; designing the study: all authors; analysing the data: KTK; interpreting the results: all authors; drafting, writing, reviewing and approving the final manuscript: all authors.

Funding The authors have not declared a specific grant for this research from any funding agency in the public, commercial or not-for-profit sectors.

Competing interests None declared.

Patient consent for publication Not required.

Ethics approval The EDHS 2016 was approved by the National Research Ethics Review Committee of Ethiopia and ICF Macro International. MEASURE DHS approval was obtained to use EDHS 2016. This analysis was approved by the University of Newcastle Human Research Ethics Committee (H-2018-0045).

Provenance and peer review Not commissioned; externally peer reviewed.

Data sharing statement There will not be any unpublished data.

Open access This is an open access article distributed in accordance with the Creative Commons Attribution Non Commercial (CC BY-NC 4.0) license, which permits others to distribute, remix, adapt, build upon this work non-commercially, and license their derivative works on different terms, provided the original work is properly cited, appropriate credit is given, any changes made indicated, and the use is non-commercial. See: http:// creativecommons.org/licenses/by-nc/4.0/.

\section{REFERENCES}

1. WHO Haemoglobin concentrations for the diagnosis of anaemia and assessment of severity. Vitamin and mineral nutrition information system. Geneva: World Health Organization, 2011.

2. Stevens GA, Finucane MM, De-Regil LM, et al. Global, regional, and national trends in haemoglobin concentration and prevalence of total and severe anaemia in children and pregnant and non-pregnant women for 1995-2011: a systematic analysis of population-representative data. Lancet Glob Health 2013;1:e16-e25.

3. Lumbiganon P, Laopaiboon M, Intarut N, et al. Indirect causes of severe adverse maternal outcomes: a secondary analysis of the WHO Multicountry Survey on Maternal and Newborn Health. BJOG 2014;121:32-9.

4. Albacar G, Sans T, Martín-Santos R, et al. An association between plasma ferritin concentrations measured $48 \mathrm{~h}$ after delivery and postpartum depression. J Affect Disord 2011;131:136-42.

5. Corwin EJ, Murray-Kolb LE, Beard JL. Low hemoglobin level is a risk factor for postpartum depression. J Nutr 2003;133:4139-42.

6. Aghamohammadi A, Zafari M, Tofighi M. High maternal hemoglobin concentration in first trimester as risk factor for pregnancy induced hypertension. Caspian J Intern Med 2011;2:194-7.

7. Zafar T. IQBAL Z iron status in preeclampsia. Professional Med J 2008;15:74-80.

8. Rahman MM, Abe SK, Rahman MS, et al. Maternal anemia and risk of adverse birth and health outcomes in low- and middle-income countries: systematic review and meta-analysis. Am J Clin Nutr 2016;103:495-504

9. Kassebaum NJ, Jasrasaria R, Naghavi M, et al. A systematic analysis of global anemia burden from 1990 to 2010. Blood 2014;123:615-24.

10. WHO. Global nutrition targets 2025: anaemia policy brief (WHO/ NMH/NHD/14.4. Geneva: World Health Organization, 2014.

11. Central Statistical Agency (CSA). Central Statistical Agency (CSA) [Ethiopia] and ICF Ethiopia demographic and health Survey 2016. Addis Ababa, Ethiopia, and Rockville, Maryland, USA: CSA and ICF, 2016.

12. Melku M, Addis Z, Alem M, et al. prevalence and predictors of maternal anemia during pregnancy in gondar, northwest Ethiopia: an institutional based cross-sectional study. Anemia 2014;2014:108593.

13. Gebremedhin S, Enquselassie F. Umeta m prevalence and correlates of maternal anemia in rural sidama, Southern Ethiopia. African Journal of Reproductive Health / La Revue Africaine de la Sant\&\#xe9; Reproductive 2014;18:44-53.

14. Kedir H, Berhane $Y$, Worku A. Khat chewing and restrictive dietary behaviors are associated with anemia among pregnant women in high prevalence rural communities in eastern Ethiopia. PLoS One 2013;8:e78601.

15. Addis Alene K, Mohamed Dohe A. Prevalence of anemia and associated factors among pregnant women in an urban area of Eastern Ethiopia. Anemia 2014;2014:561567:1-7.

16. Asres $Y$, Yemane $T$, Gedefaw L. Determinant factors of anemia among nonpregnant women of childbearing age in southwest Ethiopia: a community based study. Int Sch Res Notices 2014;2014:391580.

17. Haidar JA, Pobocik RS. Iron deficiency anemia is not a rare problem among women of reproductive ages in Ethiopia: a community based cross sectional study. BMC Blood Disord 2009;9:7.

18. Haidar J. Prevalence of anaemia, deficiencies of iron and folic acid and their determinants in Ethiopian women. J Health Popul Nutr 2010;28:359-68.

19. Umeta M, Haidar J, Demissie T, et al. Iron deficiency anaemia among women of reproductive age in nine administrative regions of Ethiopia. EthiopJHealth Dev 2008;22:252-8.

20. Pokropek C, Sobolewski P, Getachew R, et al. 621: Dietary intake patterns and insulin resistance in women with a history of gestational diabetes in the National Health and Nutrition Examination Survey (NHANES) 2000-2010. American Journal of Obstetrics and Gynecology 2015;212:S308.

21. WHO. Assessing iron status of populations: report of a joint WHO/ CDC technical consultation on the assessment of iron status at the population level. 2nd ed. Geneva: WHO, 2007.

22. Dreyfuss ML, Stoltzfus RJ, Shrestha JB, et al. Hookworms, malaria and vitamin A deficiency contribute to anemia and iron deficiency among pregnant women in the plains of Nepal. J Nutr 2000;130:2527-36.

23. Brooker S, Hotez PJ, Bundy DA. Hookworm-related anaemia among pregnant women: a systematic review. PLoS Negl Trop Dis 2008;2:e291.

24. Balarajan $Y$, Ramakrishnan U, Özaltin E, et al. Anaemia in low-income and middle-income countries. The Lancet 2011;378:2123-35.

25. Petry N, Olofin I, Hurrell RF, et al. The proportion of anemia associated with iron deficiency in low, medium, and high human 
development index countries: a systematic analysis of national surveys. Nutrients 2016;8:693.

26. Gebre A, Mulugeta A. Prevalence of anemia and associated factors among pregnant women in north western zone of tigray, northern Ethiopia: a cross-sectional study. J Nutr Metab 2015;2015:1-7.

27. Kefiyalew $F$, Zemene E, Asres $\mathrm{Y}$, et al. Anemia among pregnant women in Southeast Ethiopia: prevalence, severity and associated risk factors. BMC Res Notes 2014;7:771.

28. Rezende LF. Eluf-Neto J Population attributable fraction: planning of diseases prevention actions in Brazil. Rev Saude Publica 2016:50.

29. Bates I, McKew S, Sarkinfada F. Anaemia: a useful indicator of neglected disease burden and control. PLoS Med 2007;4:e231.

30. Lawson AB. Statistical methods in spatial epidemiology. Atrium, Southern Gate, West Sussex, England: John Wiley and Sons Inc, 2006.

31. Anselin L. Exploring Spatial Data with GeoDaTM: a workbook. center for spatially integrated social science. 2005.

32. Banerjee S. Spatial Data Analysis. Annu Rev Public Health 2016;37:47-60

33. Ord JK, Getis A. Local spatial autocorrelation statistics: distributional issues and an application. Geographical Analysis 1995;27:286-306.

34. Merlo J, Chaix B, Ohlsson $\mathrm{H}$, et al. A brief conceptual tutorial of multilevel analysis in social epidemiology: using measures of clustering in multilevel logistic regression to investigate contextual phenomena. J Epidemiol Community Health 2006;60:290-7.

35. Merlo J, Yang M, Chaix B, et al. A brief conceptual tutorial on multilevel analysis in social epidemiology: investigating contextual phenomena in different groups of people. J Epidemiol Community Health 2005;59:729-36.

36. Larsen K, Merlo J. Appropriate assessment of neighborhood effects on individual health: integrating random and fixed effects in multilevel logistic regression. Am J Epidemiol 2005;161:81-8.

37. Guo G, Zhao H. Multilevel modeling for binary data. Annu Rev Sociol 2000;26:441-62.

38. International food policy research Institute (IFPRI) and Central Statistical agency (CSA). Population and housing census atlas of Ethiopia 2007. Ethiopia: Addis Ababa, 2010.

39. Ethiopian Public Health Institute Food Consumption Survey. Ethiopian food consumption survey report. Addis Ababa, Ethiopia: Ethiopian Public Health Institute Food Consumption Survey, 2013.

40. Berhane G, Paulos Z, Tafere K, et al. Foodgrain consumption and calorie intake patterns in Ethiopia, Ethiopia strategy support program II (ESSP II). Working Paper 2011;23.

41. Ministry of Health of Ethiopia. Health and health related indicator, Vertion 1. Ethiopia: Addis Ababa, 2008.

42. Chaya N Poor Access to Health Services. Ways Ethiopia is Overcoming Research Commentary. 2007;2.

43. Mara D, Lane J, Scott B, et al. Sanitation and health. PLoS Med 2010; 7:e1000363.

44. Tay SC, Nani EA, Walana W. Parasitic infections and maternal anaemia among expectant mothers in the Dangme East District of Ghana. BMC Res Notes 2017;10:3.

45. Alaofè $\mathrm{H}$, Burney J, Naylor R, et al. Prevalence of anaemia, deficiencies of iron and vitamin $A$ and their determinants in rural women and young children: a cross-sectional study in Kalalé district of northern Benin. Public Health Nutr 2017;20:1203-13.

46. Sadeghian M, Fatourechi A, Lesanpezeshki M, et al. Prevalence of anemia and correlated factors in the reproductive age women in rural areas of tabas. J Family Reprod Health 2013;7:139-44.

47. Lover AA, Hartman M, Chia KS, et al. Demographic and spatial predictors of anemia in women of reproductive age in TimorLeste: implications for health program prioritization. PLoS One 2014;9:e91252.

48. K CG, K SK. K CG, K SK A cross-sectional study of anemia among women of reproductive age group (15- 49 years) in a rural population of Tamil Nadu. Int J Med Sci and PH 2017;6.

49. Balarajan YS, Fawzi WW, Subramanian SV. Changing patterns of social inequalities in anaemia among women in India: crosssectional study using nationally representative data. BMJ Open 2013;3:e002233.

50. Rammohan A, Awofeso N, Robitaille M-C. Addressing female irondeficiency anaemia in india: is vegetarianism the major obstacle? ISRN Public Health 2012;2012:1-8.

51. Lenz A, Olinto MT, Dias-da-Costa JS, et al. Socioeconomic, demographic and lifestyle factors associated with dietary patterns of women living in Southern Brazil. Cad Saude Publica 2009;25:1297-306.

52. USAID/ENGINE. Maternal diet and nutrition practices and their determinants: a report on formative research finding. 2014.

53. Kuche D, Singh P, Moges D, et al. Nutritional status and associated factors among pregnant women in wondo genet district, Southern Ethiopia. Journal of Food Science and Engineering 2015;5.

54. Siddiqui MZ, Goli S, Reja T, et al. Prevalence of anemia and its determinants among pregnant, lactating, and nonpregnant nonlactating women in India. SAGE Open 2017;7:215824401772555-10.

55. Soofi S, Khan GN, Sadiq K, et al. Prevalence and possible factors associated with anaemia, and vitamin B and folate deficiencies in women of reproductive age in Pakistan: analysis of national-level secondary survey data. BMJ Open 2017;7:e018007.

56. Habib MA, Raynes-Greenow C, Soofi SB, et al. Prevalence and determinants of iron deficiency anemia among non-pregnant women of reproductive age in Pakistan. Asia Pac J Clin Nutr 2018;27:195-203.

57. Bh R, Patil PS, Joseph J. Multigravidity a major risk factor of anaemia in pregnancy and its comparison in primigravida women in raichur. National J Lab Med 2017;6:PO22-PO7.

58. Al-Farsi YM, Brooks DR, Werler MM, et al. Effect of high parity on occurrence of anemia in pregnancy: a cohort study. BMC Pregnancy Childbirth 2011;11:7.

59. Kokici M, Harxhi A, Como N, et al. Haematological changes in HIV infection. Int J Ecosyst and Ecol Sci 2016;6:19-24.

60. Beyene A, Hailu T, Faris K, et al. Current state and trends of access to sanitation in Ethiopia and the need to revise indicators to monitor progress in the Post-2015 era. BMC Public Health 2015;15:451.

61. Freeman MC, Garn JV, Sclar GD, et al. The impact of sanitation on infectious disease and nutritional status: a systematic review and meta-analysis. Int J Hyg Environ Health 2017;220:928-49. 